\title{
Effect of Watering Regimen on Chlorophyll Fluorescence and Growth of Selected Green Roof Plant Taxa
}

\author{
Angela K. Durhman ${ }^{1}$ and D. Bradley Rowe ${ }^{2,3}$ \\ Department of Horticulture, Michigan State University, East Lansing, \\ MI 48824 \\ Clayton L. Rugh ${ }^{4}$ \\ Department of Crop and Soil Sciences, Michigan State University, East \\ Lansing, MI 48824
}

Additional index words. Crassulacean acid metabolism, eco-roof, drought tolerance, evapotranspiration, living roof, Sedum

\begin{abstract}
Green roofs, or vegetative or living roofs, are an emerging technology in the United States. Because environmental conditions are often more extreme on rooftops, many xerophytic plants, especially Sedum, are ideal for extensive green roofs because they are physiologically and morphologically adapted to withstand drought. A greenhouse experiment was conducted to determine the effect of watering regimens on plant stress as measured by chlorophyll fluorescence $\left(F_{v} / F_{m}\right)$, biomass accumulation, substrate moisture, and evapotransipiration on succulent plants of Sedum acre L., S. reflexum L., $S$. kamtschaticum ellacombianum Fisch., and non-Crassulacean acid metabolism (CAM) plants of Schizachyrium scoparium Nash and Coreopsis lanceolata L. Plants were grown at a substrate depth of $7.5 \mathrm{~cm}$. Results indicate even after the 4-month period, Sedum spp. survived and maintained active photosynthetic metabolism to a greater extent than Schizachyrium and Coreopsis. Furthermore, when Sedum was watered after 28 days of drought, chlorophyll fluorescence $\left(F_{v} / F_{m}\right)$ values recovered to values characteristic of the 2 days between watering (DBW) treatment. In contrast, the non-CAM plants required watering frequency every other day to survive and maintain active growth and development. Regardless of species, the greatest increase in total biomass accumulation and fastest growth occurred under the $2 \mathrm{DBW}$ regimens.
\end{abstract}

Extreme environmental conditions often found on rooftops present challenges for sustaining plant material on green roofs. Increased wind velocities, sun exposure, extreme heat, cold, shallow substrate depths, and drought usually associated with rooftops can restrict the plant palette to species capable of tolerating these harsh conditions (ASTM, 2006; Dunnett and Kingsbury, 2004; Getter and Rowe, 2006). Water availability is one of the most limiting factors for a green roof (Kirschstein, 1997). Extensive green roof systems are shallow $(5$ to $15 \mathrm{~cm})$ and lightweight (70 to $170 \mathrm{~kg} \cdot \mathrm{m}^{-2}$ ) and generally rely on natural precipitation to maintain viable plant life, although irrigation

\footnotetext{
Received for publication 10 July 2006. Accepted for publication 13 Aug. 2006.

This paper is a portion of an MS thesis submitted by Angela K. Durhman.

Funding for this study was provided by Ford Motor Company, Dearborn, Mich.; ChristenDETROIT Roofing Contractors, Detroit, Mich.; Wolfgang Behrens Systementwicklung, GmbH, Groß Ippener, Germany; and the Michigan Agricultural Experiment Station.

${ }^{1}$ Former graduate research assistant.

${ }^{2}$ Associate professor.

${ }^{3}$ To whom reprint requests should be addressed; e-mail rowed@msu.edu.

${ }^{4}$ Assistant professor.
}

systems are sometimes used during establishment or when plant health begins to decline (Dunnett and Kingsbury, 2004). The presence of drought-tolerant vegetation is essential for the longevity of extensive green roofs designed for long-term sustainability.

In the midwestern United States, there is much interest in using native species to recreate natural prairies on green roof installations. Because most of these native species are not succulents, it is questionable whether they can withstand the environmental conditions typically found on shallow extensive green roofs without irrigation. Dewey et al. (2004) evaluated 35 native grasses and wildflowers on a green roof and found that 21 species were suitable. However, these plants were grown in a substrate that was $1.0 \mathrm{~m}$ deep and irrigation was available. Many native prairie taxa are considered to be droughttolerant, but they rely on deep extensive root systems to obtain moisture-a situation that rarely exists on a green roof. Deeper substrate layers are possible, but additional costs of structural reinforcement for the building to support the added weight may be necessary.

Many xerophytic plants such as succulents are ideal for extensive green roofs because they are physiologically and morphologically adapted to withstand harsh environmental conditions (Gebauer, 1988). Some exhibit Crassulacean acid metabolism
(CAM), a physiological pathway that enables these plants to adapt to water stress conditions (Gebauer, 1988; Sayed, 2001; Ting, 1985). Because stomata are closed during the day, plant gas exchange occurs at night, thus reducing transpirational water loss. CAM plants also have fewer stomata than $\mathrm{C}_{3}$ and $\mathrm{C}_{4}$ plants (Sayed, 2001).

Some CAM plants are classified as facultative CAM (otherwise called $\mathrm{C}_{3}-\mathrm{C}_{4}$-intermediate or -inducible) in which the photosynthetic pathway can shift from $\mathrm{C}_{3}$ to CAM under stressed conditions (Kluge, 1977; Lee and Kim, 1994). Facultative CAM has been demonstrated in Sedum acre L., S. kamtschaticum ellacombianum Fisch., S. pulchellum L., S. reflexum L., and S. ruprestre L. (Lee and Kim, 1994; Sayed, 2001). Additionally, many succulents such as Sedum spp. have the capacity to store greater amounts of water in their fleshy leaves (Sayed, 2001).

In general, when a water deficit develops slowly and affects plant developmental processes, cell volume decreases and lowers turgor pressure (Taiz and Zeiger, 1998). Decreased root water potential and inhibited leaf expansion lowers plant transpiration rates to conserve water (Taiz and Zeiger, 1998). Drought stress can affect photosystem II (PS II) efficiency, decreasing the photosynthetic potential yield of the photochemical reaction (Krause and Weis, 1991). This yield can be measured as chlorophyll fluorescence, a reemittance of light energy from the PS II reaction known as the "Kautsky effect" (Bolhar-Nordenkampf et al., 1989). Measurements of chlorophyll fluorescence can detect direct effects on the photosynthetic apparatus and other physiological effects that feed back to photosynthesis (Bolhar-Nordenkampf et al., 1989). The ratio of variable fluorescence to maximum fluorescence $\left(F_{v} / F_{m}\right)$ is a relatively easy method to quantify drought stress before it becomes visually apparent (Willits and Peet, 1999).

The transpiration ratio, the reciprocal of water use efficiency, is a value that measures the effectiveness of plants in moderating water loss while allowing sufficient $\mathrm{CO}_{2}$ uptake for photosynthesis (Taiz and Zeiger, 1998). $C_{3}$ and $C_{4}$ plants generally transpire more water per molecule of $\mathrm{CO}_{2}$ fixed; thus, they exhibit a higher transpiration ratio. CAM plants have a much lower ratio, or high water use efficiency, because less water molecules are lost when $\mathrm{CO}_{2}$ is fixed. However, although CAM plants are more likely to survive, their lower rates of evapotranspiration (ET) could diminish the ability of a green roof system to mitigate stormwater runoff and provide cooling to the building underneath. Plant species can influence stormwater retention and evaporative cooling resulting from differences in shading and rates of transpiration (Dunnett et al., 2005).

Regarding drought tolerance, several studies have demonstrated that Sedum spp. commonly outperform other potential green roof taxa (Dunnett and Nolan, 2004; Durhman et al., 2004; Gómez-Campo and Tortosa, 1994; Lassalle, 1998; Monterusso et al., 
2005; Rowe et al., 2005, 2006; VanWoert et al., 2005). Even so, identifying taxa other than Sedum spp. suitable for green roofs could expand the list of plant species and reduce the potential problems associated with monocultures. Knowledge of water requirements for individual plant species is important in choosing green roof vegetation type and maintaining plant health. Therefore, the objective of this study was to determine the effect of watering regimen on plant stress of selected CAM and non-CAM green roof plant taxa as measured by chlorophyll fluorescence, biomass accumulation, substrate moisture, and evapotranspiration.

\section{Materials and Methods}

A drought tolerance study comparing three species of Sedum and two non-CAM plants was conducted at the Plant Science Greenhouses at Michigan State University, East Lansing, Mich. The experiment was a two-way factorial design consisting of five species, five watering regimens, and an unvegetated control treatment to aid in tracking water use. There were seven replications of each treatment for a total of 175 pots. Pots were arranged in a completely randomized design with a single nonsampled border row consisting of vegetated and unvegetated control pots surrounding the study.

Plastic pots $(11 \mathrm{~cm} \times 11 \mathrm{~cm} \times 12$-cm deep $)$ were fitted with a green roof filtration drainage layer (XF108) and vegetation carrier (XF301) (Wolfgang Behrens Systementwicklung, GmbH, Groß Ipener, Germany). Total thickness of the drainage layer and vegetation carrier was $\approx 3.75 \mathrm{~cm}$. This system allowed excess water from the retention fabric and planting media to drain through the nylon coils and exit the pot without losing substrate (Fig. 1).

Pots were filled with media to a depth of $7.5 \mathrm{~cm}$. Media consisted of $40 \%$ heat-expanded slate (gradation of $3 \mathrm{~mm}$ to $5 \mathrm{~mm}$ ) (PermaTill; Carolina Stalite Company, Salisbury, N.C.), 40\% United States Golf Association (USGA) grade sand (Osburn Industries, Taylor, Mich.), 10\% Michigan peat (Osburn Industries), 5\% dolomite (Osburn Industries), $3.33 \%$ composted yard waste (Kalamazoo Landscape Supplies, Kalamazoo, Mich.), and $1.67 \%$ composted poultry litter (Herbruck's,

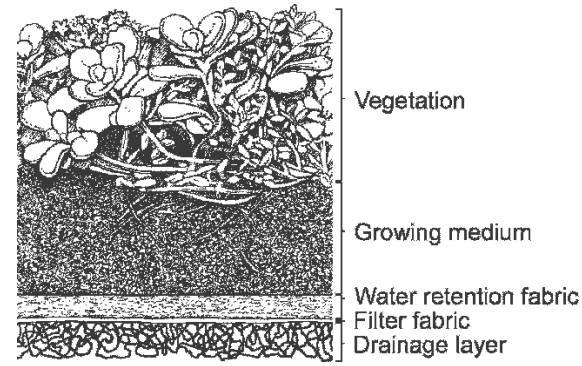

Fig. 1. Cross-section representative of an extensive green roof system used in the study. Substrate depths tested were $2.5 \mathrm{~cm}, 5.0 \mathrm{~cm}$, and $7.5 \mathrm{~cm}$.
Saranac, Mich.). At time of planting, EC and $\mathrm{pH}$ of the media were $3.29 \mathrm{mmho} / \mathrm{cm}$ and 7.9 , respectively. All treatments had $100 \mathrm{~g} \cdot \mathrm{m}^{-2}$ of Nutricote type $100,20 \mathrm{~N}-7 \mathrm{P}_{2} \mathrm{O}_{5}-10 \mathrm{~K}_{2} \mathrm{O}$ controlled release fertilizer (Agrivert, Webster, Tex.) hand-applied at the time of planting.

Seeds of Sedum acre L. (biting stonecrop), $S$. reflexum L. (crooked stonecrop), S. kamtschaticum ellacombianum Fisch. (stonecrop), Schizachyrium scoparium Nash (little bluestem), and Coreopsis lanceolata L. (lanceleaf coreopsis) were sown on 14 Jan. 2003. Seeds of $S$. acre, $S$. reflexum, and $S$. kamtschaticum ellacombianum were sown at rates of $1 \mathrm{~g} \cdot \mathrm{m}^{-2}$, $0.5 \mathrm{~g} \cdot \mathrm{m}^{-2}$, and $0.5 \mathrm{~g} \cdot \mathrm{m}^{-2}$, respectively. The non-CAM species Schizachyrium scoparium, a Michigan native perennial grass, and $\mathrm{Co}$ reopsis lanceolata, a Michigan native perennial forb, were planted at a rate of 10 seeds/pot and then thinned to one seedling/pot. Seeds of $S$. scoparium and C. lanceolata were obtained from Prairie Nursery (Westfield, Wisc.), whereas Sedum seed was provided by Jelitto Staudensamen, GmbH (Schwarmstedt, Germany). As a result of its extremely small size, seeds of Sedum were mixed in dry sand before application to ensure even distribution within each pot. Plants germinated, established, and grew for an 85-d period and were watered daily for the first $20 \mathrm{~d}$ to keep the substrate moist and then once every other day for the next $65 \mathrm{~d}$. Plants were considered established when they covered $90 \%$ of the substrate surface. Coreopsis lanceolata and S. scoparium were selected for this study because they showed promise when grown on unirrigated green roof platforms in East Lansing, Mich. (Monterusso et al., 2005; Rowe et al., 2006). This also allowed us to include a non-CAM broadleafed perennial and grass in the study in addition to the CAM succulents.

After the establishment period, watering regimen factors of $2,7,14,28$, or $88 \mathrm{~d}$ between watering (DBW) were randomly assigned to each pot. All plants received a consistent amount of water, $157 \mathrm{~mL}$, with each watering, which converted to $13 \mathrm{~mm}$ of precipitation. Excess water was allowed to drain out of the pot.

During both the establishment and data collection periods, natural lighting in the greenhouse was supplemented with 400-W incandescent bulbs for a 16 -h photoperiod. Average light meter (model LI-250; LI-COR, Inc., Lincoln, Neb.) measurements at canopy height ranged from $338.4 \mu \mathrm{mol} \cdot \mathrm{s}^{-1} \cdot \mathrm{m}^{-2}$ to $897.1 \mu \mathrm{mol} \cdot \mathrm{s}^{-1} \cdot \mathrm{m}^{-2}$. Air temperature was controlled by a thermostat set at $21 \pm 1{ }^{\circ} \mathrm{C}$.

Data collection. Data collection began on 10 April 2003. Measurements were taken daily the first $7 \mathrm{~d}$ of the study, every other day from days 9 to 33, and once a week until the study was ended on day 89. Each data collection event included measuring chlorophyll fluorescence, soil moisture, and whole pot weights to calculate evapotranspiration before the watering treatment.

To establish an initial mean dry weight of the biomass, a representative subsample of five pots per species was selected and harvested on the first day of the study. The above-ground biomass was destructively harvested at the substrate interface and dried for $144 \mathrm{~h}$ at $60{ }^{\circ} \mathrm{C}$. On completion of the study, 89 days later, shoots from every treatment were destructively harvested and dried at $60{ }^{\circ} \mathrm{C}$. Biomass accumulation was calculated as the difference between the mean initial (subsample) and final shoot dry weights.

A Hansatech plant efficiency analyzer (PEA) was used to measure chlorophyll fluorescence induction by the high timeresolution continuous-excitation principle (Hansatech Instruments, Ltd., Norfolk, U.K.). Each plant was dark-adapted for 10 minutes before measurement and illuminated with a $50 \%$ light level. Maximum quantum efficiency of PS II was recorded $\left(\mathrm{F}_{\mathrm{v}} / \mathrm{F}_{\mathrm{m}}\right)$. Single leaf blades of $S$. scoparium, C. lanceolata, and $S$. kamtschaticum were randomly selected and measured while attached to the plant. Leaf blades of $S$. acre and $S$. reflexum were randomly selected and excised from the plant to be dark-adapted and measured. This was necessary because the PEA clips were not secure on the leaf while still attached to the whole plant. The standard error for this method was \pm 0.03 .

Substrate moisture was monitored throughout the study by inserting a theta probe (ML2x, Delta-T Devices, Ltd., Cambridge, U.K.) into the media until the points of the prongs contacted the vegetation carrier. The theta probe instrument has a range of 0.0 to $1.0 \mathrm{~m}^{3} \cdot \mathrm{m}^{-3}$ with accuracy of \pm 0.01 $\mathrm{m}^{3} \cdot \mathrm{m}^{-3}$ for values from 0.05 to $0.6 \mathrm{~m}^{3} \cdot \mathrm{m}^{-3}$. However, accuracy was likely lower for values below $0.05 \mathrm{~m}^{3} \cdot \mathrm{m}^{-3}$ (Delta-T Devices, Ltd.). Soil moisture was taken to evaluate water availability for the plants and determine the amount of time it takes for treatments to reach complete dehydration.

Evapotranspiration values were derived from pot weight measurements over the first week of the study, as described in VanWoert et al. (2005). An estimate of water retention by each pot was measured by pot weight before and after watering on the first day. For the rest of the week, pot weights were taken directly before the watering event.

Statistical analysis. Chlorophyll fluorescence data were analyzed by PROC GLM, least significant differences (1sd) with a Tukey-Kramer adjustment (SAS version 8.02; SAS Institute Inc., Cary, N.C.). Evapotranspiration values derived from pot weights and soil moisture data were subjected to repeated measures using an unstructured covariance structure (PROC MIXED). Total shoot dryweight and shoot biomass percent accumulation data were analyzed by PROC MIXED, lsd with a Tukey-Kramer adjustment.

\section{Results and Discussion}

Chlorophyll fluorescence. Watering regimen influenced $\mathrm{F}_{\mathrm{v}} / \mathrm{F}_{\mathrm{m}}$ as values decreased for plants grown under the less frequent watering regimens (Fig. 2). This occurred for the three species of Sedum at the 88 DBW regimen and at all watering regimens longer than 2 DBW 

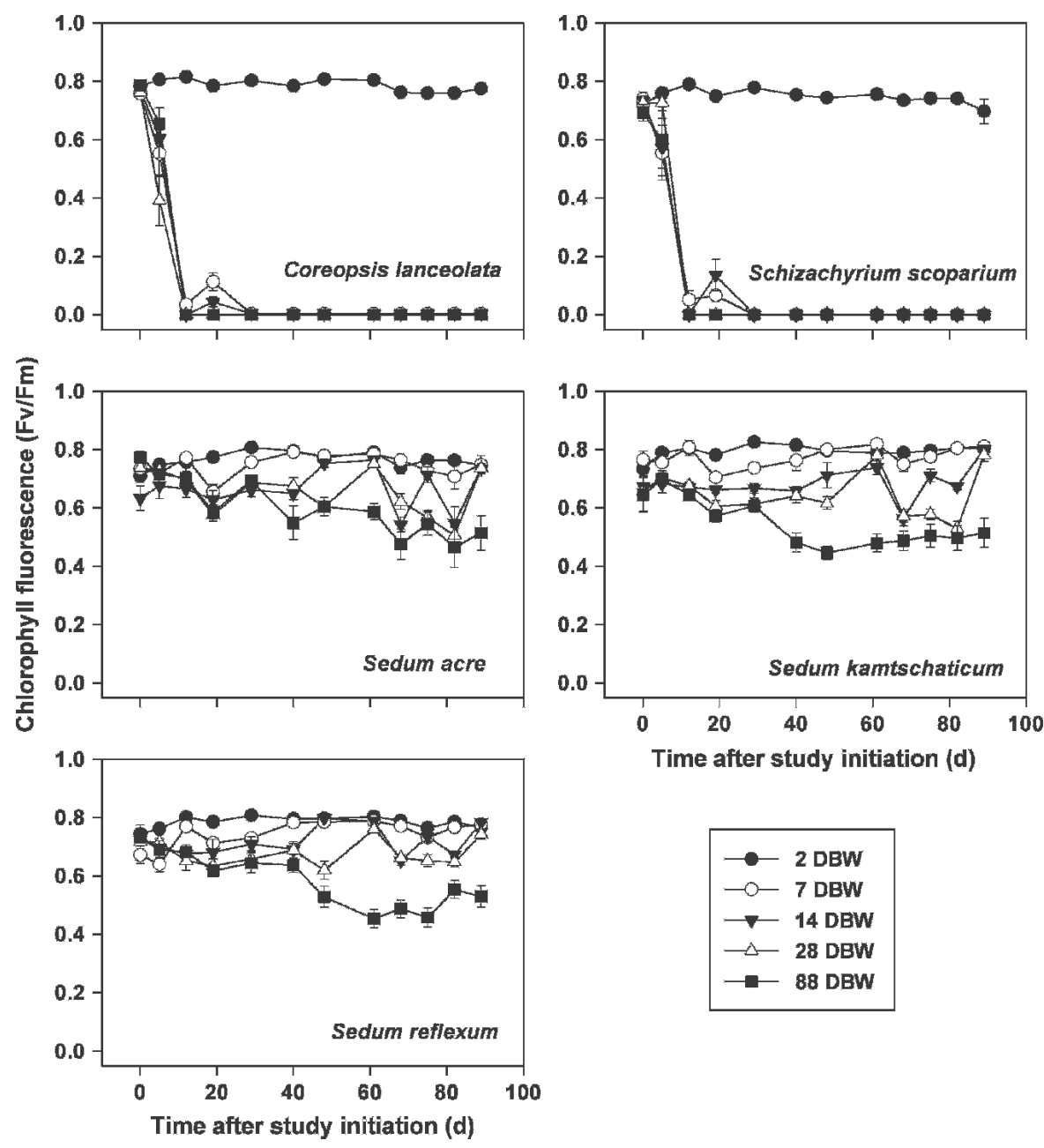
regimens of $2 \mathrm{~d}$ between watering (DBW), 7 DBW, 14 DBW, 28 DBW, and 88 DBW $(n=7)$. Taxa included three CAM (Sedum acre, S. kamtschaticum, and S. reflexum) and two non-CAM species (Coreopsis lanceolata and Schizachyrium scoparium). Measurements were recorded before each watering event. Error bars represent standard error.

for C. lanceolata and S. scoparium. The three species of Sedum maintained active photosynthetic capacity and survived the 4-month period, including those plants that were never watered during the 88-d period. In contrast, the non-CAM plants, C. lanceolata and S. scoparium, died unless they received water every other day.

The three species of Sedum exhibited similar $\mathrm{F}_{\mathrm{v}} / \mathrm{F}_{\mathrm{m}}$ trends throughout the study, much different from the non-CAM species. The mean $\mathrm{F}_{\mathrm{v}} / \mathrm{F}_{\mathrm{m}}$ was 0.758 for $S$. acre under the $2 \mathrm{DBW}$ over the entire study. Although all Sedum behaved similarly, S. acre exhibited slightly higher $\mathrm{F}_{\mathrm{v}} / \mathrm{F}_{\mathrm{m}}$ values than either S. kamtschaticum ellacombianum or $S$. reflexum. In the most extreme drought treatment of $88 \mathrm{DBW}$, the $\mathrm{F}_{\mathrm{v}} / \mathrm{F}_{\mathrm{m}}$ values for $S$. acre fell under 0.500 only twice during the course of the study, occurring first on day 68 . In contrast, S. kamtschaticum ellacombianum and $S$. reflexum $\mathrm{F}_{\mathrm{v}} / \mathrm{F}_{\mathrm{m}}$ values fell below 0.500 more often and earlier, by day 40 and day 50 , respectively. The data suggest $S$. acre may be more drought-tolerant than $S$. kamtschaticum ellacombianum and $S$. reflexum.
One interesting observation was the recovery rate for the three species of Sedum after watering events. On watering the 28 DBW regimen, Sedum $\mathrm{F}_{\mathrm{v}} / \mathrm{F}_{\mathrm{m}}$ values returned to those values characteristic of the $2 \mathrm{DBW}$ treatments. At the end of the 3-month period, there was no difference $(P \leq 0.05)$ in chlorophyll fluorescence between $2 \mathrm{DBW}$ and 28 DBW postwatering.

In contrast, all $\mathrm{F}_{\mathrm{v}} / \mathrm{F}_{\mathrm{m}}$ values for $C$. lanceolata and $S$. scoparium declined rapidly by day 4 for all watering regimens except 2 DBW (Fig. 2). Over the 89-d study, the average $\mathrm{F}_{\mathrm{v}} / \mathrm{F}_{\mathrm{m}}$ ratio for $C$. lanceolata was 0.793 for the $2 \mathrm{DBW}$ treatment. However, for all other watering treatments, both $C$. lanceolata and $S$. scoparium reached a permanent wilting point by day 33 . These results complemented the results of Lasaalle (1998) in which S. album outperformed Festuca glauca Vill. and Chrysanthemum leucanthemum L. in response to watering regimens.

Every species is unique and will vary in biologic activity in response to environmental conditions, but Sedum are especially drought-tolerant. In controlled greenhouse studies, VanWoert et al. (2005) reported that six species of Sedum survived 88 d without water and Teeri et al. (1986) reported that S. rubrotinctum R. T. Clausen (stonecrop) survived for 2 years without water. Sedum species are able to tolerate drought, maintain functional photosynthetic systems, and survive relative to $C$. lanceolata and $S$. scoparium because they demonstrate facultative $\mathrm{CAM}$ and are efficient in water use. In contrast, $S$. scoparium and $C$. lanceolata exhibit $\mathrm{C}_{4}$ and $\mathrm{C}_{3}$ plant physiology in response to the natural environments they live in. They also possess different growth habits and morphologies because both are upright growers with greater relative leaf area than any of the sedums. Under extensive green roof conditions with a shallow depth of $7.5 \mathrm{~cm}$, watering frequency greater than $7 \mathrm{DBW}$ was necessary for plant growth and development for C. lanceolata and S. scoparium.

Because drought tolerance is one of the most limiting factors on extensive green roof systems given their shallow substrate depths $(<10 \mathrm{~cm})$, CAM plants have a distinct advantage. In this study, the two non-CAM species were expected to be less drought-tolerant when grown in $7.5 \mathrm{~cm}$ of substrate because of their greater height and bulky morphology. However, non-CAM taxa exhibiting similar growth forms and morphology are potential candidates. As a general rule, potentially suitable species can be found by looking at the microclimate (media depth, solar levels, water availability, and so on) of the green roof in question and comparing it with a plant's native habitat. Dunnett and Kingsbury (2004) suggest that species that evolved in extreme conditions such as mountainous terrains, high-altitude environments, coasts, limestone substrates, or semideserts are probably suitable for green roof habitation. Further studies need to be conducted with non-CAM species that fit these criteria.

Biomass accumulation. The greatest increase in biomass generally occurred under the 2 DBW regimens. This is especially evident for the non-CAM plants where drought conditions created by $7,14,28$, and 88 DBW permitted little biomass accumulation (Table 1). The result confirms the observation that non-CAM plants, $C$. lanceolata and $S$. scoparium, were dead within $33 \mathrm{~d}$ of the study if they did not receive the 2 DBW treatment. Similarly, S. acre and S. kamtschaticum ellacombianum exhibited a decrease in biomass accumulation when they were watered less than 14 and $7 \mathrm{~d}$, respectively.

Sedum reflexum accumulated greater biomass than the other species under the 88 DBW regimen (Table 1). Among the three sedum, S. acre and S. kamtschaticum ellacombianum were most affected by watering regimen. One explanation is that $S$. kamtschaticum ellacombianum has been documented to grow in less xeric conditions than S. reflexum (Kirschstein, 1997; Stephenson, 2002). Additionally, S. kamtschaticum ellacombianum has more spreading shoots and a wide, broad, and thin leaf structure, presenting a thicker canopy than either $S$. acre or 
S. reflexum, whose leaves are linear and crowded against the stem (Eggli and Hartmann, 2003). This may result in higher water demands. Neither explanation accounts for why $S$. acre did not behave similarly to $S$. reflexum considering they have similar morphologies.

With adequate watering, all plants displayed healthy and consistent growth and development. When considering planting a mixture of different plant species for a green roof, plants that require frequent watering could be planted in areas designed with zoned irrigation or in deeper substrates. However, with watering intervals of $7 \mathrm{~d}$ or more, growth was not significant for $C$. lanceolata, S. scoparium, or S. kamtschaticum ellacombianum. The phenomenon of a decrease in biomass accumulation supports findings from VanWoert et al. (2005), which could be attributed to the high demand of water needs required by larger vegetation. Potential degradation of nonstructural carbohydrates within the plants could have occurred after the establishment period in response to a lack of water (Taiz and Zeiger, 1998).

Substrate moisture. Observed volumetric substrate moisture content was typical of sandy soils. Initial content after a watering event was as high as $0.34 \mathrm{~m}^{3} \cdot \mathrm{m}^{-3}$. However by day 5 , no pots had detectable substrate moisture except for those that received the 2 DBW treatment (Fig. 3).

Comparing substrate moisture among treatments on the last day of the study, pots with $S$. acre and $S$. reflexum held more moisture under the 2-DBW regimen than those of S. kamtschaticum ellacombianum, $S$. scoparium, C. lanceolata and the unvegetated control under the same regimen (Fig. 3). Additionally, pots of $S$. acre held greater moisture than all other species under the 7-DBW treatment. The result may be because $S$. acre and $S$. reflexum have lower water requirements; therefore, the plants did not take up as much water, which allowed moisture to be retained in the substrate. Additionally, above-ground biomass for $S$. acre and $S$. reflexum was located closer to the substrate surface and may have contributed to shading, reducing evaporation from the substrate. The shading effect was reported in previous research showing intervals between irrigation could be increased after canopy closure of 'Impulse Rose' Impatiens (Impatiens wallerana L.) grown in containers (Lohr and Pearson-Mims, 2001). Sedum kamtschaticum ellacombianum had the highest biomass in the 2 DBW attributed to its numerous spreading stems and broad flat leaves, which may have contributed to higher water needs. Schizachyrium scoparium and C. lanceolata did not produce a dense canopy so there was minimal shading to reduce evaporation losses.

In a similar study comparing substrate types and vegetation effect on substrate moisture, VanWoert et al. (2005) reported that, in general, substrates with vegetation contained more water than the unvegetated treatment. However, in this study, a loose trend can be seen between vegetation type

Table 1. Shoot dry weight biomass accumulation (g) for Sedum, Coreopsis, and Schizachyrium within each watering regimen over the course of the study.

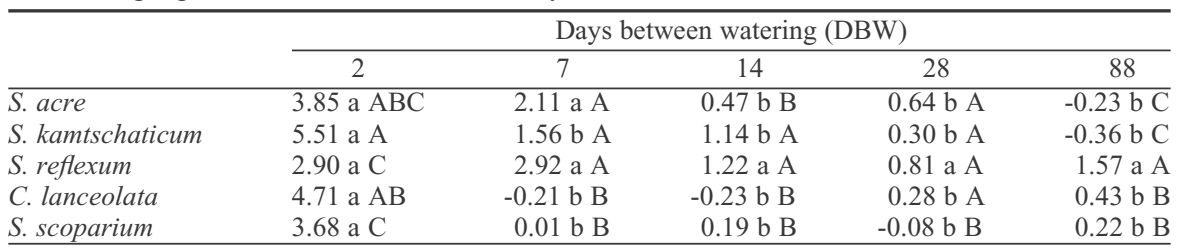

Means followed by different lowercase letters (within rows) or uppercase letters (within columns) are significantly different $(P \leq 0.05)$.
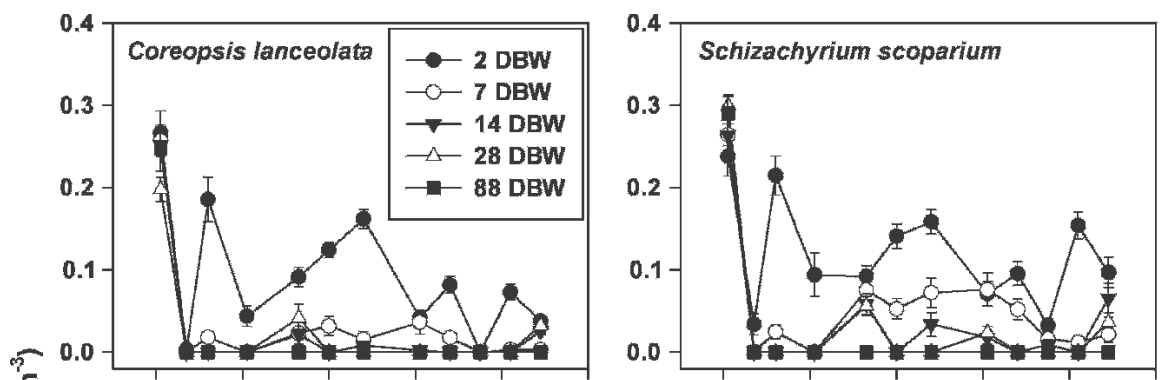

E
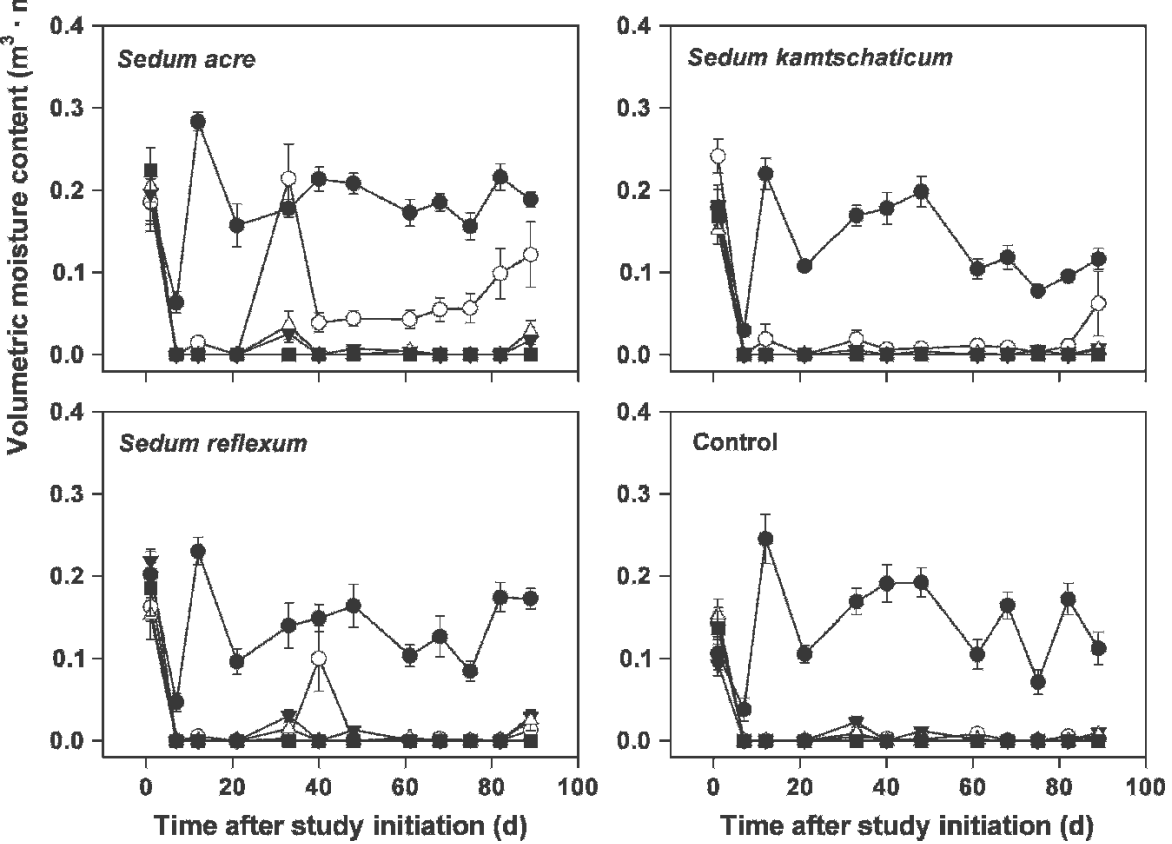

Fig. 3. Substrate volumetric moisture content $\left(\mathrm{m}^{3} \cdot \mathrm{m}^{-3}\right)$ for five species and a nonvegetated control collected over the 88-d study for five watering regimens of $2 \mathrm{~d}$ between watering (DBW), $7 \mathrm{DBW}$, $14 \mathrm{DBW}, 28 \mathrm{DBW}$, and $88 \mathrm{DBW}(\mathrm{n}=7)$. Taxa included three CAM (Sedum acre, S. kamtschaticum, and $S$. reflexum) and two non-CAM species (Coreopsis lanceolata and Schizachyrium scoparium). Measurements were recorded before each watering event. Error bars represent standard error.

and substrate moisture. By the end of the experiment, sufficient biomass had accumulated to compare the vegetation types with substrate moisture. Substrate in pots of C. lanceolata had significantly less substrate moisture than the other species, including $S$. scoparium (Fig. 3). However, pots of $S$. acre consistently retained the most moisture.

Evapotranspiration. As a result of the variability in the data collection dates, ET was analyzed daily for the first week of the study (Fig. 4). ET rates were highest on the day of watering and lower on the second day; however, a gradual increase over the first week occurred under the 2 DBW regimen. Coreopsis lanceolata was most affected by watering regimen because ET values were higher on the day of watering, relative to Sedum, and fell to the lowest value after the water treatment. This is probably the result of its large leaf area compared with the other species.

For all species, receiving no water for $6 \mathrm{~d}$ resulted in lower ET rates (between 0.1 and $0.2 \mathrm{~mm} \cdot \mathrm{d}^{-1}$ ) (Fig. 4). Surprisingly, over the course of the first week of drought, $S$. scoparium exhibited higher ET rates compared with $C$. lanceolata. This may be the result of the differences in water use efficiencies, differences in drought tolerance, and leaf surface area. The $7 \mathrm{DBW}$ results contrast VanWoert et al. (2005) in which rates dropped to $0.0 \mathrm{~mm} \cdot \mathrm{d}^{-1}$ for Sedum spp. mixture. This difference is likely the result of 

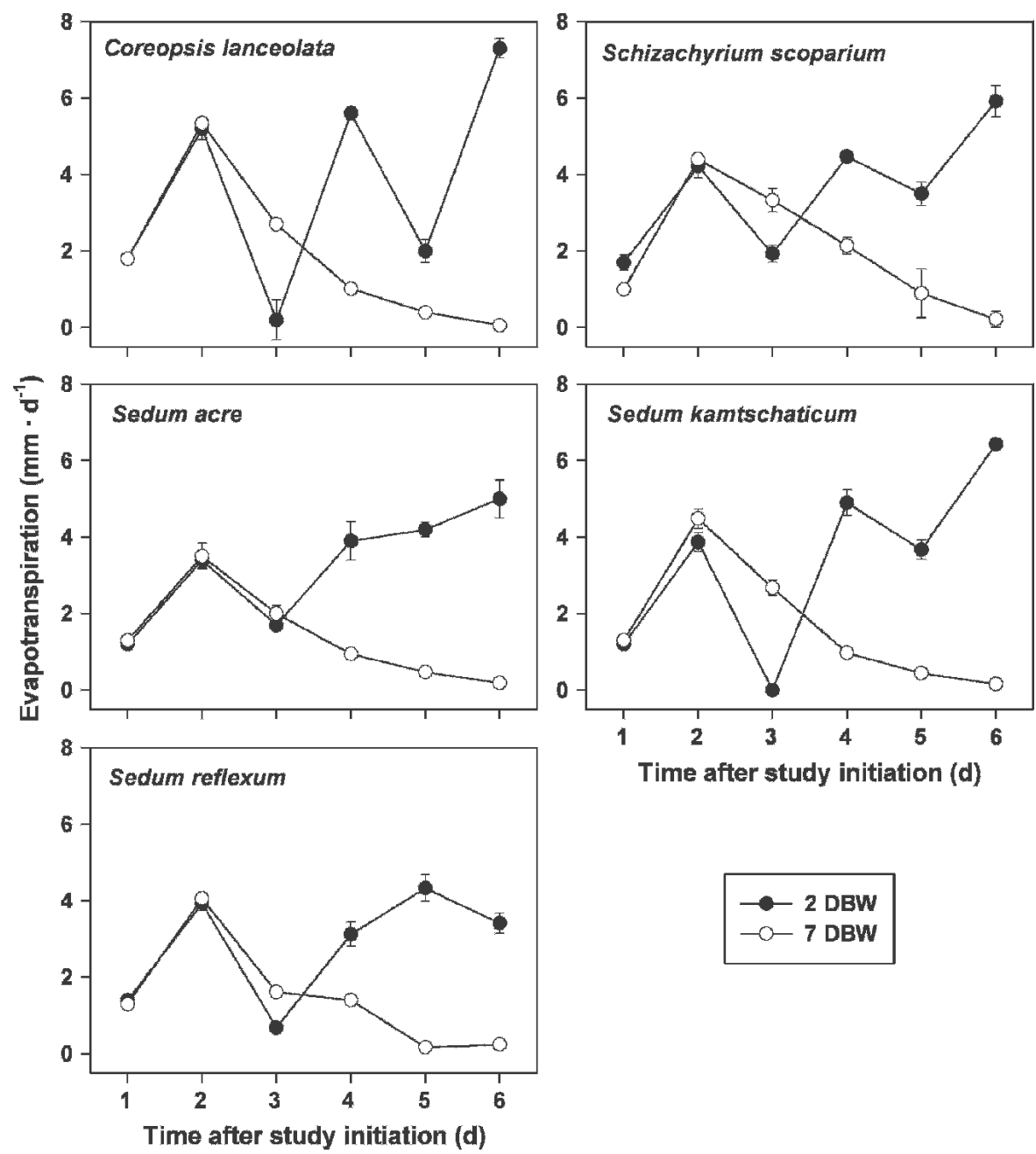

Fig. 4. Evapotranspiration values $\left(\mathrm{mm} \cdot \mathrm{d}^{-1}\right)$ over the first week of the study for watering regimens of $2 \mathrm{~d}$ between watering (DBW) and 7 DBW. Taxa included three CAM (Sedum acre, S. kamtschaticum, and $S$. reflexum) and two non-CAM species (Coreopsis lanceolata and Schizachyrium scoparium). Error bars represent standard error.

differences in substrate composition and depth because greenhouse conditions were comparable. In the VanWoert study, the substrates evaluated were depths of $2 \mathrm{~cm}$, $2 \mathrm{~cm}$ with an extra moisture retention fabric layer capable of retaining $1200 \mathrm{~g} \cdot \mathrm{m}^{-2}$ of water, and $6 \mathrm{~cm}$.

ET rates presented for 2 and $7 \mathrm{DBW}$ are probably conservative compared with measurements taken outdoors. In the natural environment, climatic variables are altered by solar radiation and wind in which ET rates are directly related. However, observations under controlled greenhouse conditions allow for general assumptions to be made in regard to drought stress.

Although CAM species such as sedum are well suited for green roofs in terms of survival, they may not be the best choice to capitalize on the environmental benefits that green roofs can provide. Given an adequate water supply through natural rainfall or supplemental irrigation, species with higher transpiration rates would remove more water from the roof-growing substrate. This would presumably enhance the evaporative cooling effect provided by the green roof and reduce energy consumption during the summer. In addition, the growing substrate would be able to retain a greater amount of stormwater, thus reducing runoff.

\section{Conclusion}

CAM species such as Sedum acre, $S$. reflexum, and $S$. kamtschaticum ellacombianum do not require as much water to maintain plant vigor and metabolic activity compared with the non-CAM species Schizachyrium scoparium and Coreopsis lanceolata. Sedum plants sustained photosynthetic activity over a period of 4 months without watering, although biomass was reduced relative to more frequently watered treatments. One can assume that under frequent watering regimens, the non-CAM plants can remain photosynthetically active and continue growth and development. However, they need irrigation more frequently than once every $7 \mathrm{~d}$ to remain photosynthetically active over prolonged periods.

Based on greenhouse results, relative irrigation recommendations may be derived for CAM versus non-CAM species. The result from this study can be extrapolated to many other succulents, herbaceous forbs, and grasses by considering their photosynthetic processes, life-form characteristics, and growth habits for use on an extensive green roof system. Additionally, a method of measuring photosynthetic yield such as chlorophyll fluorescence is effective in evaluating plant stress and can be used in green roof applications to maintain plant health and vigor while minimizing excess water use.

\section{Literature Cited}

ASTM E 2400. 2006. Standard guide for selection, installation, and maintenance of plants for green roof systems. ASTM International, West Conshohocken, $\mathrm{Pa}$.

Bolhar-Nordenkampf, H.R., S.P. Long, N.R. Baker, G. Oquist, U. Schreibers, and E.G. Lechner. 1989. Chlorophyll fluorescence as a probe of the photosynthetic competence of leaves in the field: A review of current instrumentation. Funct. Ecol. 3:497-514.

Dewey, D., P. Johnson, and K. Kjelgren. 2004. Species composition changes in a rooftop grass and wildflower meadow. Native Plants. 5:56-65.

Dunnett, N. and N. Kingsbury. 2004. Planting green roofs and living walls. Timber Press, Inc, Portland, Ore.

Dunnett, N., A. Nagase, R. Booth, and P. Grime. 2005. Vegetation composition and structure significantly influence green roof performance, p. 287-296. Proc. of 3rd North American Green Roof Conference: Greening Rooftops for Sustainable Communities Washington, D.C. 4-6 May 2005. The Cardinal Group, Toronto.

Dunnett, N. and A. Nolan. 2004. The effect of substrate depth and supplementary watering on the growth of nine herbaceous perennials in a semi-extensive green roof. Acta Hort. 643:305-309.

Durhman, A., N.D. VanWoert, D.B. Rowe, C.L. Rugh, and D. Ebert-May. 2004. Evaluation of Crassulacean species on extensive green roofs, p. 504-517. Proc. of 2nd North American Green Roof Conference: Greening Rooftops for Sustainable Communities, Portland, Ore. 2-4 June 2004. The Cardinal Group, Toronto.

Eggli, U. and H.E. Hartmann. 2003. Illustrated handbook of succulent plants Crassulaceae, Springer, N.Y.

Gebauer, G. 1988. Carbon, nitrogen and water-use of $\mathrm{C} 3, \mathrm{C} 4$, and CAM plants: Comparative aspects. Acta Hort. 229:73-84.

Getter, K.L. and D.B. Rowe. 2006. The role of green roofs in sustainable development. HortScience 41:1276-1285.

Gómez-Campo, C. and L. Tortosa. 1994. Especies vegetales en las asoteas verdes. Agricultura (Espana) 749:1041-1042.

Kirschstein, C. 1997. Die dürreresistenz einiger Sedum-arten. Abgeleitet aus der Bedeutung der Wurzelsaugspannung-Teil 1. Stadt und Grün 46:252-256.

Kluge, M. 1977. Is Sedum acre L. a CAM plant? Oceologia. 29:77-83.

Krause, G.H. and E. Weis. 1991. Chlorophyll fluorescence and photosynthesis: The basics. Annu. Rev. Plant Phys. Plant Mol. Biol. 42:313-349. 
Lassalle, F. 1998. Wirkung von trockenstreß auf xerophile pflanzen. Stadt und Grün. 47:437-443.

Lee, K.S. and J. Kim. 1994. Changes in Crassulacean acid metabolism (CAM) of Sedum plants with special reference to soil moisture conditions. J. Plant Biol. 37:9-15.

Lohr, V.I. and C. Pearson-Mims. 2001. Mulching reduces water use of containerized plants. HortTechnology 11:277-278.

Monterusso, M.A., D.B. Rowe, and C.L. Rugh 2005. Establishment and persistence of Sedum spp. and native taxa for green roof applications. HortScience 40:391-396.

Rowe, B., M. Monterusso, and C. Rugh. 2005 Evaluation of Sedum species and Michigan native taxa for green roof applications. p. 469-481. Proc. of 3rd North American Green Roof Conference: Greening Rooftops for Sustainable Communities, Washington, D.C. 4-6 May 2005. The Cardinal Group, Toronto.

Rowe, D.B., M.A. Monterusso, and C.L. Rugh 2006. Assessment of heat-expanded slate and fertility requirements in green roof substrates. HortTechnology 16:471-477.

Sayed, O.H. 2001. Crassulacean acid metabolism 1975-2000, a checklist. Photosynthetica 39:339-359.

Stephenson, R. 2002. Sedum: Cultivated stonecrop. Timber Press, Inc, Portland, Ore.

Taiz, L. and E. Zeiger. 1998. Plant physiology. 2nd ed. Sinauer Associates, Inc, Sunderland, Mass.
Teeri, J., M. Turner, and J. Gurevitch. 1986. The response of leaf water potential and Crassulacean acid metabolism to prolonged drought in Sedum rubrotinctum. Plant Physiol. 81:678680.

Ting, I. 1985. Crassulacean acid metabolism. Annu. Rev. Plant Physiol. 36:595 622.

VanWoert, N.D., D.B. Rowe, J.A. Andresen, C.L. Rugh, and L. Xiao. 2005. Watering regime and green roof substrate design affect Sedum plant growth. HortScience 40:659-664.

Willits, D. and M. Peet. 1999. Using chlorophyll fluorescence to model leaf photosynthesis in greenhouse pepper and tomato. Acta Hort. 507:311-317 